\title{
Gestão Autônoma da Medicação, do Quebec ao Brasil: uma aposta participativa
}

\author{
Gaining Autonomy \& Medication Management, from Quebec to \\ Brazil: a participatory commitment
}

Analice Palombini1, Lourdes Rodriguez del Barrio²

DOI: $10.1590 / 0103-1104202112816$

RESUMO Este artigo apresenta o contexto e os modos de construção da versão brasileira do Guia da Gestão Autônoma da Medicação (Guia GAM-BR), comparativamente ao Guia originário do Quebec. O Guia GAM-BR foi resultado de parceria estabelecida entre Brasil e Canadá que, por meio de uma pesquisa multicêntrica, transpôs ao contexto brasileiro o instrumento quebequense, a serviço dos usuários da saúde mental, visando ao aumento do seu poder de negociação em seus tratamentos medicamentosos. Tal transposição implicou mais do que 'adaptação': tratou-se da 'transformação' do Guia originário em um instrumento brasileiro. Entre essas transformações, destacam-se: substituição do 'eu' pelo 'você' como sujeito do enunciado das questões apresentadas pelo Guia; maior desenvolvimento do tema dos direitos; supressão das orientações para retirada progressiva da medicação. Além disso, o dispositivo grupal fez-se imanente à estratégia GAM brasileira. Longe de significar traição, tais transformações mantêm-se fiéis à forma participativa e cogestiva que orientou a elaboração da GAM na sua origem, como encarnação da experiência democrática e cidadã própria ao Quebec. Assim, o artigo busca colocar em análise a produção dos efeitos da estratégia GAM em solo brasileiro, na consideração à experiência democrática e ao processo de reforma psiquiátrica no Brasil.

PALAVRAS-CHAVE Conduta do tratamento medicamentoso. Saúde mental. Participação da comunidade.

1 Universidade Federal do Rio Grande do Sul (UFRGS) - Porto Alegre (RS), Brasil. analice.palombini@gmail. com

2 Universidade de Montreal (UM) - Quebec, Canadá.

\begin{abstract}
This article presents the context and construction of the Brazilian version of the Gaining Autonomy \& Medication Management Guide (GAM-BR) compared to Quebec's original Guide. The GAM-BR Guide resulted from a partnership between Brazil and Canada, which transposed the Quebec instrument to the Brazilian context through multicenter research to empower mental health users in the negotiation of their drug treatment. This process was more than an adaptation as it transformed the original Guide into a Brazilian instrument. The main changes were replacing ' $I$ ' with 'you' as the subject of the statements in the Guide, further developing the theme of rights, suppressing the guidelines for the progressive withdrawal of medication. Additionally, the group device became immanent to the Brazilian GAM strategy. Far from being a betrayal, this set of changes remains loyal to the participatory and co-managerial process that oriented the elaboration of the GAM at its origin as an embodiment of Quebec's typical democratic and citizen experience. Therefore, this article aims to analyze the production of the GAM strategy's effects of in Brazil, considering its democratic experience and the psychiatric reform in the country.
\end{abstract}

KEYWORDS Medication therapy management. Mental health. Community participation. 


\section{Introdução}

No intuito de alcançar as especificidades da experiência em saúde mental em terras brasileiras de que trata este artigo, voltamos o olhar a elementos da nossa história cujos efeitos perduram até os dias atuais, incidindo também sobre o modo das relações estabelecidas entre profissionais e usuários de saúde mental. É sabido que o Brasil detém um dos piores índices de distribuição de renda do mundo ${ }^{1,2}$, responsável por brutal desigualdade social - com repercussão em indicadores como nível de escolarização e acesso a bens culturais $^{3}$ - que atinge a maioria pobre da população e, mais duramente, à maioria negra. A acumulação da riqueza se faz acompanhar de alto grau de concentração do poder, excluindo da vida político-institucional do País a maior parte da sua população adulta, que permanece, assim, alheia aos espaços instituídos da polis, enquanto a classe dominante compreende o exercício do poder político como parte de seus privilégios inalienáveis ${ }^{4}$ - trata-se, ainda aqui, de herança colonial que institui o poder da família patriarcal em detrimento de um estado democrático de direito.

A definição de homem cordial, cunhada por Sérgio Buarque de Holanda ${ }^{5}$ para definir o caráter das relações sociais no Brasil, é a expressão desse uso familiarista dos espaços de poder, calcado em interesses pessoais: cordial é esse sujeito que regula, para si e para os seus, benefícios e privilégios, desconhecendo os sentidos de universalidade e equidade imanentes às noções de democracia, cidadania, liberdade política e esfera pública. A isso, vem somar-se a herança escravagista que se atualiza na naturalização da desigualdade e no racismo que - embora denegado - é estruturante da sociedade brasileira, assegurando a manutenção do privilégio branco em todas as suas instâncias ${ }^{6}$. A dominação econômica e política das elites é assim exercida com extremas coerção e brutalidade, mesmo quando revestida de gestos de familiarismo e intimidade. Esse é o quadro político do Brasil, o qual, recorrentemente, tem imposto, à força de golpes, uma curta existência às experiências de caráter democrático popular da sua vida republicana recente, o que não significa ausência de lutas e resistência por parte da população.

Com efeito, é em um contexto de mobilização que o movimento antimanicomial tem surgimento, já no final da década de 1970, como uma entre muitas expressões da luta pela redemocratização do País. Nos anos 1960-1970, enquanto eclodiam no mundo ocidental movimentos de reforma das instituições psiquiátricas e de desinstitucionalização da loucura, a ditadura civil-militar do Brasil provocava um aumento exponencial da população nos manicômios, além de multiplicar o número de hospitais psiquiátricos privados conveniados com o Estado; e era contra essa realidade que se erguia o movimento dos trabalhadores em saúde mental, desembocando na luta antimanicomial7. Na esteira do movimento pela reforma sanitária, que garantiu, no texto da Constituição de 1988, a inclusão da saúde como direito do povo e dever do Estado e a criação do Sistema Único de Saúde (SUS), o movimento da luta antimanicomial conquistou a implementação de uma política nacional de saúde mental de caráter reformista - comunitário e psicossocial ${ }^{8}$.

Contudo, essas conquistas, na arena política em que foram disputadas, no cruzamento entre redemocratização e neoliberalismo ${ }^{2}$, não alcançaram toda a radicalidade de seus princípios. O SUS, de caráter integral, universal e equitativo, convive com uma assistência suplementar à saúde, de caráter privatista. Ademais, a participação popular na definição dos rumos da política de saúde no País, um dos seus princípios de base, encontra enormes dificuldades para concretizar-se: o que se convencionou chamar de "controle social" viu-se, em regra, restrito aos espaços dos conselhos e conferências de saúde, cujas formas de organização, quando não seu aparelhamento pelo Estado, tendem a impedir a participação, de fato, da população que mais se utiliza dos serviços de saúde 9 . Já no que diz respeito à 
saúde mental, a rede de serviços, dispositivos e programas propostos pela política nacional em substituição à lógica manicomial convive com a manutenção de parte ainda significativa do antigo parque manicomial e seus hospitais psiquiátricos, públicos ou privados, e, além disso, não foi capaz de reverter nem a ênfase nem o modo - verticalizado e não participativo - dos tratamentos medicamentosos. Assim, apesar do caráter ampliado da clínica proposta pelos movimentos reformistas, o cuidado em saúde mental segue frequentemente reduzido ao tratamento medicamentoso, sem que os usuários conheçam os motivos ou tenham possibilidade de decidir a respeito ${ }^{10}$.

Buscando incidir sobre esse último aspecto, entre 2009 e 2014, uma parceria estabelecida entre Brasil e Canadá (Aliança Internacional de Pesquisas entre Universidade e Comunidade Saúde Mental e Cidadania) elaborou a versão brasileira do Guia da Gestão Autônoma da Medicação (Guia GAM-BR) - instrumento a serviço dos usuários da saúde mental visando ao aumento do seu poder de negociação a propósito de seus tratamentos medicamentosos com os profissionais com quem se tratam. Além de reiterar o direito ao consentimento livre e esclarecido para utilização de psicofármacos, a GAM expressa reconhecimento do saber que advém da experiência de uso do medicamento, encarnada pelo usuário em seu próprio corpo"1.

A abordagem GAM desenvolveu-se nos anos 1990, no Quebec, pelos organismos comunitários - serviços alternativos de saúde mental e grupos de direitos dos usuários - em parceria com a universidade. Foi um longo processo de reflexão, pesquisa e ação, envolvendo usuários, trabalhadores e pesquisadores em diferentes etapas até a sua consolidação e a constituição de uma rede de transferência de conhecimento, acompanhamento e apoio às experiências GAM entre os chamados serviços alternativos do Quebec e no setor público ${ }^{12}$.

Sua versão brasileira concretizou-se, por sua vez, na parceria entre universidade, associação de usuários e familiares e serviços da rede pública de saúde mental, em especial os Centros de Atenção Psicossocial (Caps). O processo de construção do Guia GAM-BR envolveu múltiplos esforços de tradução, entre Quebec e Brasil, mas também entre os diferentes estados e grupos de pesquisa brasileiros participantes e entre acadêmicos, trabalhadores e usuários: de uma língua a outra, de uma cultura a outra, de um ponto de vista a outro ${ }^{\mathbf{1 3}}$. Além disso, diferenças socioeconômico-culturais entre os dois países fizeram do esforço de adaptação do Guia GAM à realidade brasileira uma experiência radical10, a qual não caberia mais nomear de 'adaptação'; tratou-se, antes, da 'transformação' do Guia originário do Quebec em um instrumento brasileiro.

Com efeito, a GAM não configura modelo a ser aplicado, mas estratégia que, ao abrir espaços de fala, atualiza seus princípios: reconhecimento da dignidade da pessoa e respeito aos seus direitos; afirmação do direito de recusar o tratamento proposto sem abdicar do cuidado; reivindicação de acesso a práticas alternativas em saúde mental. Transformar o Guia GAM, como ocorreu no Brasil, era manter-se fiel aos princípios que orientaram sua criação, levada a cabo de forma participativa e cogestiva, como encarnação da experiência democrática e cidadã própria ao Quebec, no cruzamento entre um comum e o singular, entre sujeito de direitos e sujeito de desejo.

Este artigo visa apresentar o contexto e os modos de construção do Guia GAM-BR, sinalizando suas diferenças em relação ao Guia original e colocando em análise a produção de seus efeitos em solo brasileiro na consideração às particularidades da experiência democrática no Brasil. Dá-se continuidade, assim, à interlocução estabelecida entre Quebec e Brasil, base da metabolização da GAM em nosso país, num movimento dialógico análogo àquele em que se forjam as democracias participativas, com canais de discussão que possibilitam a participação popular na tomada de decisões políticas. 


\section{Material e métodos}

O processo de tradução e transformação do Guia GAM para o contexto brasileiro envolveu a realização de duas etapas interligadas de pesquisa, seguindo as normas brasileiras de regulamentação de pesquisa envolvendo seres humanos, com aprovação 222/2009 do Comitê de Ética em Pesquisa da Faculdade de Ciências Médicas da Universidade Estadual de Campinas.

A primeira etapa da pesquisa, realizada entre 2009 e 2011, ocupou-se de elaborar uma primeira versão brasileira do Guia, a partir da tradução e adaptação do texto original. Essa adaptação inicial, prévia à etapa de intervenção nos serviços de saúde mental, deu-se em encontros presenciais mensais com participação dos seis pesquisadores das universidades envolvidas e acadêmicos a eles vinculados, entre os quais alguns trabalhadores da rede de saúde mental de Campinas (cidade sede da pesquisa); em torno de cinco usuários de Campinas e dois do Rio de Janeiro, participantes de movimentos sociais e de projetos culturais protagonizados por usuários da saúde mental. Com base em duas traduções independentes do guia original, cotejadas nesses encontros, o texto foi lido e debatido entre os três segmentos reunidos, tendo sido propostas alterações importantes quanto ao seu conteúdo já nessa etapa.

O Guia GAM assim traduzido e adaptado foi utilizado em grupos de intervenção realizados em três Caps nos estados de São Paulo (SP), Rio de Janeiro (RJ) e Rio Grande do Sul (RS), respectivamente, com participação de usuários e moderação de pesquisadores e trabalhadores do serviço. Um quarto grupo realizou-se na universidade, com integrantes da associação de usuários e familiares e moderação de pesquisadores e trabalhadores da rede de saúde mental de Campinas.

A primeira versão do Guia GAM-BR foi construída a partir dessa experiência de uso do Guia preliminarmente traduzido e adaptado, sua avaliação crítica e as modificações propostas pelos usuários, trabalhadores e pesquisadores participantes, as quais foram debatidas em reuniões multicêntricas mensais, com a presença desses três segmentos, oriundos dos três centros integrantes da pesquisa ${ }^{\mathbf{1 0}}$.

A segunda etapa da pesquisa, de 2011 a 2014, acompanhou o uso do Guia GAM na versão finalmente estabelecida pela primeira etapa. O seu desenvolvimento teve variações de um centro de pesquisa a outro, mas seguiu ocorrendo em serviços de saúde mental e em grupo, convocando ao diálogo os seus diversos atores, nos três estados (RS, SP e RJ). Da avaliação crítica dessa experiência, resultou uma revisão final do Guia e a formulação do 'Guia do Moderador', com diretrizes para sua utilização em processos grupais. Tanto a versão final do Guia GAM-BR ${ }^{14}$ quanto o Guia do Moderador ${ }^{15}$ foram disponibilizados on-line, para uso livre.

\section{Resultados e discussão}

O relato acima, na intenção de ser breve, não faz jus ao enorme desafio implicado no esforço de proceder às múltiplas traduções que se fizeram necessárias para o 'abrasileiramento' do Guia GAM construído no Quebec. Cabe salientar que, embora ao menos uma das transformações da GAM em solo brasileiro tenha se efetuado por força de adaptação à conjuntura, as demais se impuseram como expressão da perspectiva participativa e cogestiva que orienta a própria estratégia.

Contudo, Guerini13 alerta para o perigo de, no esforço de adaptação, sucumbirmos a um projeto homogeneizante de sociedade. Resistir a esse projeto, segundo a autora, envolve conduzir o exercício de tradução entre as culturas em direção à criação de um plano comum, não uniforme nem universalizante, "sempre possível de ser aberto e sempre ameaçado por tendências de fechamento"13(63); envolve também o trânsito entre os diferentes mundos produzidos por cada perspectiva a partir da qual emerge um sujeito. 
Esse desafio acompanhou a pesquisa e orienta nosso olhar ao buscar identificar o que singulariza a versão brasileira do Guia GAM na relação ao Guia quebequense. Organizamos em dois tópicos nossa exposição, referente aos dois momentos de transformação da ferramenta: antes e depois da experiência dos grupos de intervenção.

\section{Transformação prévia do texto: linguagem e coletivo, direitos e cidadania}

Modificações mais substanciais ao texto do Guia GAM foram feitas no momento inaugural da pesquisa, antes dos grupos de intervenção, com participação de acadêmicos, trabalhadores e usuários, conforme referido acima. Essas modificações disseram respeito fundamentalmente ao sujeito dos enunciados, ao tema dos direitos e às instruções para retirada progressiva da medicação.

A transposição do texto francês para o português implicou uma primeira e mais imediata tomada de decisão: a substituição do 'eu' pelo 'você' como sujeito do enunciado das questões apresentadas pelo Guia. O guia original é construído como uma ferramenta para autorreflexão, o que justifica o uso do 'eu' nas questões propostas e o possessivo que acompanha o título, na capa: 'Mon guide personnel'16. Já o Guia GAM-BR ${ }^{14}$, após o título 'Gestão Autônoma da Medicação', abre espaço para que cada usuário tome posse dele, inserindo seu nome no lugar que lhe é reservado: 'Este Guia pertence a: '. Pensamos que assumir seu nome próprio e inscrevê-lo na capa do Guia - tornando-o seu - é, por si, ato de cidadania, especialmente significativo para uma parcela de brasileiros destituída de posses e sem acesso a bens culturais. No entanto, a alteração que se anuncia na capa já sinaliza a mudança de perspectiva com que se enunciam as questões que o texto contém, deslocando-se de uma posição autorreflexiva para a posição dialógica: o Guia GAM não se enuncia como voz da consciência, mas como interlocutor outro com quem o usuário conversa, que lhe coloca questões e o faz pensar sobre seu cotidiano e sua relação com a experiência da medicação. Assim, por exemplo, a primeira parte do Guia, na versão brasileira, recebe o nome de 'Sua qualidade de vida' em lugar de 'Ma qualité de vie', e questões como 'De quelle façon je prende soin de moi?' foram modificadas para 'Como você cuida de si mesmo?'. Cabe destacar que, enquanto na edição do Guia GAM do Quebec na qual baseamos nossa tradução e adaptação, apenas à página 3 , intitulada 'Ton guide', a perspectiva dialógica é colocada em causa, na edição atualizada, publicada em 2017 no Quebec ${ }^{17}$, há uma alternância entre autorreflexão e dialogia ao longo de todo o Guia, como reverberação da modificação realizada pela experiência brasileira.

No Brasil, tal mudança foi proposta pelos pesquisadores acadêmicos no início do trabalho de adaptação da tradução e imediatamente assentida por trabalhadores e usuários, sem que chegasse a se tornar objeto de discussão. Podemos elencar uma série de razões que nos conduziram, tão prontamente, a realizar essa modificação. Um fator decisivo remete-nos à definição prévia das formas e do contexto de experimentação do Guia traduzido: com usuários de Caps, em processo grupal, a se desenvolver no próprio serviço. $\mathrm{O}$ grupo constituiu-se em dispositivo fundamental por meio do qual pôde operar a estratégia GAM no contexto brasileiro - a construção de grupalidade é um dos temas-chave abordados no 'Guia do Moderador'15. Aqui, interessa-nos destacar o liame entre linguagem e coletivo, pelo qual a ideia de um discurso monológico não vigora. É Bakhtin ${ }^{18}$ quem nos ensina que toda enunciação é produto da interação dialógica da sociedade: não há texto que não aluda a outros que o antecederam e que não incite outros que virão. Nesse sentido, a voz do outro, o discurso da alteridade, habita e povoa a voz de cada um; mesmo um monólogo em primeira pessoa carrega uma polifonia de vozes $^{19}$. Porém, pareceu-nos importante explicitar essa dialogia no enunciado das questões 
propostas pelo Guia GAM, dando lugar a um exercício de pensamento, de reflexão de si, que se faz em copresença, junto e ao lado de outros. No contexto brasileiro, essa copresença foi importante fator de aprendizagens e encorajamentos mútuos entre usuários participantes dos grupos GAM para defesa de seus direitos e para o exercício da cidadania no cotidiano das relações com os serviços de saúde e com as suas famílias.

Em relação ao tema dos direitos, levou-se em conta que a democracia, no Brasil, tem sido insuficiente para abranger o conjunto da sua população; além de insuficiente, tem-se mostrado frágil, sujeita a golpes recorrentes. Para muitos brasileiros, cidadania e direitos são termos em abstrato, que não encontram expressão no cotidiano de suas vidas. Não é diferente para usuários dos serviços de saúde mental. Lembremos que, apesar da rede de serviços abertos e territorializados que o SUS e uma política de saúde mental fizeram avançar; até 2005 , o maior volume de investimentos públicos em saúde mental esteve direcionado aos hospitais psiquiátricos ${ }^{20}$. A experiência de tratamento em um Caps revelou-se um fato novo para muitos desses usuários que antes só haviam podido conhecer as injunções do tratamento médico-hospitalar. Era preciso, portanto, oferecer-lhes instrumentos que permitissem compreender que essa novidade representava um direito mais do que benevolência dos profissionais. Era preciso informar-lhes quais direitos lhes eram assegurados como usuários do sistema de saúde. Para tanto, além da copresença, materializada na forma dialógica do texto do Guia e na coletivização do seu uso, foi importante dar maior ênfase ao tema dos direitos que, no Guia do Quebec, resumia-se a uma página. Aqui também vale a ressalva de que a edição atualizada do Guia quebequense ${ }^{\mathbf{1 7}}$ ampliou significativamente $o$ tema dos Direitos, trazendo-o, porém, à frente, como primeiro passo do Guia, enquanto no Guia brasileiro ele compõe o terceiro passo, que trata das redes de apoio e da ampliação da autonomia.
Finalmente, há uma modificação que toca em um ponto crucial da proposição do Guia GAM do Quebec. Trata-se da exclusão, na versão brasileira, da parte que, no Guia original, oferece instruções, a partir de uma tomada de decisão do usuário, para reduzir progressivamente e de modo seguro a quantidade de medicamentos ingerida, até a sua eliminação. A versão brasileira

deslocou o foco da retirada ou redução do remédio, para o da negociação, e a segunda parte do Guia foi reescrita, visando o incremento da participação do usuário na gestão do seu tratamento ${ }^{10(972) .}$

As razões alegadas para essa alteração apontam, de um lado, a posição manifesta pelos usuários participantes desde a primeira etapa da pesquisa de que o problema não era "o direito de interromper o uso de medicamentos, mas o direito de ter acesso a eles" (os usuários expressavam aqui sua consciência de um direito de cidadania - o do acesso aos bens necessários à vida - que não lhes era assegurado); de outro, a escolha em realizar a pesquisa por dentro do Estado, isto é, em serviços de saúde mental vinculados ao SUS, implicando negociação pela qual "concede-se ao Estado ao mesmo tempo em que se força o Estado a conceder"21(28). Considerando o cenário da política de saúde mental no País, cujo projeto reformista, apesar dos seus avanços, não evitou que o tratamento farmacológico mantivesse lugar central e frequentemente exclusivo entre as ofertas terapêuticas, os pesquisadores avaliaram que a pesquisa se inviabilizaria na rede de serviços se mantivesse a proposta do Guia original na íntegra. Havia também o temor, no tocante aos psiquiatras pesquisadores, de que o Conselho de Medicina, órgão fiscalizador da profissão de caráter eminentemente conservador, reagisse mal à proposta do Guia, imputando-lhes de pronto a acusação de 'exercício antiético' da profissão.

É possível afirmar que nós, pesquisadores brasileiros, cedemos ao Estado ao abandonar 
a afirmação da possibilidade - a mais radical e concreta - de o usuário decidir pela retirada dos medicamentos; e forçamos, ou pretendemos forçar, o Estado, na figura dos seus agentes - profissionais e serviços de saúde - a conceder o reconhecimento dos direitos dos usuários, a participação efetiva destes na formulação do seu projeto terapêutico, o exercício de cidadania no cotidiano dos serviços. Elementos presentes no ideário da reforma sanitária no Brasil, direitos, participação, cidadania forjam as ideias de autonomia e protagonismo - de trabalhadores e usuários - no SUS, em tensão com a função reguladora e de controle das populações pelo Estado. Contudo, corremos, inevitavelmente, o risco das capturas. Assim, em uma perspectiva neoliberal e privatizante da saúde, a ideia de protagonismo ou autonomia deságua na responsabilização individual do sujeito por seu adoecimento, bem como pelos cuidados à sua própria saúde. Ora, pautada na 'lógica do cuidado', conforme referida por Annemarie $\mathrm{Mol}^{22}$, a decisão de interromper o uso de psicofármacos é uma responsabilidade compartilhada que requer acompanhamento profissional. Ao excluir da versão brasileira a segunda parte do Guia GAM original, poupamos os serviços e suas equipes de tomar contato com ela, livrando-os de ter de responder, coletivamente, à perspectiva de retirada dos medicamentos - os usuários tornam-se os únicos responsáveis por essa decisão, conforme ao que Mol irá denominar de 'lógica da escolha', privatizante e individualista ${ }^{22}$.

Transcorridos dez anos desde essa tomada de decisão, julgamos ter hoje acúmulo suficiente para colocar em experimentação, no contexto brasileiro, as orientações para redução e/ou retirada da medicação, levando a termo o exercício integral de direitos previsto na 'Carta dos direitos dos usuários da saúde' do SUS ${ }^{23}$. Assim, em 2018, um projeto multicêntrico, envolvendo diversas universidades públicas do País, foi submetido a edital de fomento com esse objetivo (embora considerado de excelência pela avaliação entre pares, não obteve financiamento para sua realização).

\section{Entre brasileiros: conflitos e negociação}

Modificações ulteriores propostas ao Guia GAM - com base na experimentação da sua versão traduzida e previamente transformada - voltaram-se especialmente a escolha e adequação de termos e ao ordenamento das perguntas. A dinâmica das discussões foi marcada de forma particular pela intervenção dos usuários na tomada de decisões. Em geral, eram intervenções que, impondo-se a partir de um sentido singular da experiência, vinham interromper lógicas instituídas do pensamento ou o círculo às vezes vicioso das discussões entre acadêmicos e eventualmente trabalhadores. Assim foi com a palavra 'Guia', que dá nome, desde sua origem no Quebec, a esse instrumento. Trabalhadores de um dos Caps participantes da pesquisa questionavam o uso desse termo, argumentando que a experiência da psicose poderia levar os usuários a tomar a palavra 'guia' numa acepção imperativa, determinando de forma absoluta os passos a seguir. Sugeriam, no seu lugar, a palavra 'caderno' que, por sua vez, era recusada por parte dos acadêmicos e trabalhadores presentes à reunião multicêntrica em que esse debate acontecia, sob o argumento de que 'caderno' remeteria ao contexto escolar, o que não era pertinente e poderia soar como infantilização dos usuários. A discussão corria o risco de se tornar infindável, não fosse a intervenção, à certa altura, de um dos usuários presentes que, batendo na mesa como para chamar a palavra para si, afirmou em alto e bom som: "Caderno vem com nada escrito, livro já vem todo escrito, no guia a gente lê, mas também escreve, então é guia!"10(972). Os demais usuários assentiram: a preocupação com a palavra guia não encontrava eco na experiência que haviam tido. À primeira vista intempestiva e aleatória, a intervenção do usuário introduziu na conversa um terceiro termo - 'livro' -, até então inaudito, mas capaz de produzir um deslocamento nos polos da discussão, de maneira que 'guia' passava a ser o termo mediano de 
uma nova polaridade envolvendo 'caderno' e 'livro'. Foi, de fato, uma intervenção precisa e a tempo, que bastou para pôr fim à querela.

Encerrar a discussão não significou, porém, evitar a multiplicidade semântica que o termo 'guia' carrega; tratou-se antes de poder suportá-la. Curiosamente, a tese de Jorge $\mathrm{Melo}^{\mathbf{2 4}}$, ao construir de forma primorosa a narrativa de um primeiro encontro de grupo GAM (na segunda etapa da pesquisa), apresenta-nos uma usuária a brincar com a semântica da palavra 'guia', enquanto os pesquisadores, buscando retomar o prumo da situação, respondem tratar-se 'apenas de um caderno'. A citação direta do seu texto, para além de explicitar esse ponto, dá pistas da dinâmica grupal que anima a experiência GAM no Brasil, colocando em cena elementos da cultura local, afrodiaspórica, a perpassar a roda e seus participantes.

PRIMEIRO ENCONTRO. Aquela gente de fora continua a falar arrastado, com jeito de sabichão, pergunta se a gente sabe o que tá fazendo ali. A gente sabe que tá ali para falar de remédio, que é um estudo, uma pesquisa, mas continua a sentir certa indefinição do que fazer ali e de que forma. Dizem os doutores que tem um guia para ajudar não só os usuários, como a equipe do Caps também. Ali ao lado, uma companheira começa a esboçar um rosto de espanto. Ela se levanta de repente, tomada de certo nervosismo, querendo saber que negócio era esse de guia. Num é coisa de macumba? Ih, não vai dar pra ficar ali não, ela não serve pra isso, pra negócio de macumba. Quase sem pausa, a companheira corre para o centro do círculo e começa a dançar como se estivesse em um terreiro, os braços cadenciando semicírculos alternados para frente e para trás, as pernas cruzando-se nos passos igualmente alternados, sob o corpo curvado. Arrastada por tambores inaudíveis, a gente explode em risadas por toda a roda. Em uma breve situação, o grupo demonstra sua proximidade com aquilo que o círculo subjaz, isto é, com a roda, que ali se transmuta imediatamente em terreiro.
Sem qualquer constrangimento, a companheira põe-se à frente e desposa temporariamente $o$ centro de uma zona de influência com a qual ela parece não ter problemas em manejar. Diverte-se com isso, enquanto diverte aos demais. Limpando as lágrimas de riso, alguns procuram se recompor. Começam então a pedir respeito às crenças, pois com isso não se brinca, é coisa pra se tomar cuidado! Um tanto perdidos no campo de um jogo que se faz por outras vias, os pesquisadores limitam-se a sorrir e a tranquilizar o grupo de que não se tratava de macumba, mas apenas de um caderno com informações e perguntas para ajudar a pensar o tema da medicação ${ }^{24(68-69)}$.

Outra expressão colocada em discussão foi a frase 'Eu sou uma pessoa, não uma doença' que dá início ao texto do Guia original ${ }^{16}$. $\mathrm{O}$ argumento de alguns acadêmicos, de que a frase operava uma dicotomia - 'ou pessoa ou doença' - que talvez não fizesse sentido aos usuários, foi derrubado pelo depoimento eloquente de uma usuária a respeito da importância que essa frase adquiriu na sua vida, acrescido do comentário de outro usuário, de que "não se pode negar que há uma doença”10(973).

A participação dos usuários, porém, não ocorreu apenas no sentido da conservação do texto proposto. Chamou-lhes atenção a pouca ênfase dada, no texto original, aos temas do trabalho e dos relacionamentos sexuais e amorosos, que julgavam de importância crucial em suas vidas e que eram tão afetados pela experiência do adoecimento e da medicamentalização. Assim, propuseram a inclusão de perguntas específicas sobre esses temas. Em relação aos relacionamentos, cuidaram de deixar expressa, na formulação da questão, 'vida sexual' e 'vida amorosa' como duas esferas distintas da experiência (mas que poderiam se unir), sobre as quais incidiam os efeitos colaterais dos medicamentos.

Por último, a preocupação com a simplificação do texto, evitando frases longas e palavras difíceis, presente desde as modificações preliminares da tradução do Guia, seguiu operando 
na elaboração dessa versão do Guia GAM-BR, bem como na sua revisão crítica, levada a cabo na etapa seguinte da pesquisa, conforme já relatado. Com efeito, o baixo grau de escolarização e o pouco acesso à leitura que caracterizam a população brasileira colocam desafios importantes quanto à compreensão do texto escrito e de alguns termos caros ao campo da reforma psiquiátrica, como autonomia e protagonismo. O dispositivo grupal foi crucial também no enfrentamento das dificuldades de leitura ou iletramento de muitos usuários, os quais, ao lado daqueles capazes de leitura e escrita, podiam sentir-se, eles próprios, leitores: do Guia, dos contextos de vida, das suas experiências...

\section{Efeitos GAM em solo brasileiro}

A acolhida da pesquisa nos Caps teve como facilitador a longa trajetória de atuação no campo da saúde mental por parte dos pesquisadores envolvidos. No entanto, o tema enunciado - 'Gestão Autônoma da Medicação' - era novo, suscitando expectativas e temores diversos, tanto por parte de usuários como dos trabalhadores. Houve quem acreditasse tratar-se de estímulo à automedicação, enquanto outros supunham que era pesquisa de um novo medicamento, com farto financiamento de algum laboratório farmacêutico. Desfeitos os mal-entendidos, apesar da receptividade inicial e, por vezes, da sinalização positiva ou manifestação de interesse para realização da pesquisa nos serviços contatados, os grupos de intervenção não se desenvolveram sem percalços, exigindo negociação continuada com as equipes. Enquanto os trabalhadores que se envolveram com a condução desses grupos com os pesquisadores eram bastante tocados pela experiência, capaz de transformar tanto aos usuários quanto a si próprios, os demais profissionais das equipes permaneciam ou alheios ou desconfiados do que ali se passava. Se alguns entre esses podiam reconhecer mudanças positivas na atitude dos usuários do grupo, que se mostravam mais conscientes de seus direitos e intentavam maior participação nas decisões a respeito de seus tratamentos, outros ou não percebiam essas mudanças ou as consideravam indesejáveis. Porém, os efeitos produzidos entre trabalhadores e usuários na etapa inaugural da pesquisa possibilitaram sua replicação na etapa seguinte, com inclusão de um número maior de serviços e participação de usuários, trabalhadores e residentes na moderação dos grupos de intervenção.

Além disso, desde 2013, quando o Guia GAM-BR foi disponibilizado ao público via internet e, no RS, por iniciativa da Secretaria Estadual da Saúde, distribuído às coordenadorias regionais para uso pelos serviços interessados, as experiências têm-se multiplicado, com variações em seus espaços, suas formas e seus participantes, alcançando também usuários de álcool e outras drogas e crianças e adolescentes ${ }^{25}$. Em alguns casos, à semelhança dos mal-entendidos iniciais com a expressão gestão autônoma da medicação, a expectativa dos trabalhadores ao proporem um grupo GAM é de produzir adesão aos tratamentos medicamentosos - autonomia sendo aqui identificada à capacidade do usuário de tomar seus medicamentos sem necessitar da ajuda de terceiros. Entretanto, têm sido outros os efeitos recolhidos da experiência dos usuários, em que se destaca, além do maior conhecimento sobre os efeitos dos medicamentos, uma tomada de consciência sobre os direitos que lhes concernem.

Uma análise das primeiras publicações brasileiras da pesquisa GAM revela que, após participação nos grupos de intervenção, os usuários demonstraram maior conhecimento sobre sua medicação e passaram a reconhecer em si um saber advindo da experiência, pelo qual não somente aos médicos, mas também a si próprios, era atribuída autoridade no que diz respeito ao tratamento medicamentoso. Porém, seguiram considerando os profissionais como autoridade superior, detentora do poder de decisão sobre o tratamento. Em todos os campos da pesquisa, houve usuários que buscaram conversar com seus médicos visando 
a ajustes da medicação, mobilizados e encorajados pelas discussões nos grupos GAM. De modo geral, o intuito era de que a medicação pudesse ser diminuída, mas não retirada. A prescrição medicamentosa mantinha-se soberana na formulação do projeto terapêutico; mesmo tornando-se capazes de identificar seus limites e danos, os usuários preferiam sofrer dos efeitos colaterais a viver sem os medicamentos: "Se não tomar o remédio, a gente fica pior"10,26(120),27.

Além disso, o fato de se fazerem capazes, a partir da GAM, de expressar suas ideias e reivindicar seus direitos aos trabalhadores não significou, segundo os usuários, que tenham sido ouvidos. Na percepção destes, o aumento de suas exigências em relação ao tratamento produziu tensões e enfrentamentos com as equipes, em relação às quais afirmaram a necessidade de serem mais bem preparadas para lidar com a negociação do projeto terapêutico de cada um. A experiência GAM suscitou o esforço nascente dos usuários em tomar parte das decisões referentes aos seus tratamentos, colocando-os, ao mesmo tempo, em contato com o limite dos serviços para acolher e dar lugar a essa participação, em especial no que diz respeito ao tratamento medicamentoso. Essa experiência também tornou visível o desconhecimento sobre medicamentos que recai sobre profissionais não prescritores, que igualmente identificaram dificuldades na relação com os médicos para obterem mais informações sobre o tratamento medicamentoso dos usuários. Ainda, a experiência GAM fez com que usuários olhassem criticamente para a forma como, nos Caps, a noção de tratamento era equiparada ao uso regular de medicamentos. Embora outros recursos fossem mencionados, não alcançavam o mesmo valor dado ao tratamento farmacológico ${ }^{\mathbf{2 1}, 28}$.

Os usuários referiram-se ao grupo GAM como espaço de troca de experiências sobre o medicamento, em que cada um podia contar sua vivência singular com a medicação e um saber experiencial lhe ser reconhecido. A experiência GAM contrastava com a forma de comunicação dos profissionais que os atendiam e que os usuários puderam então criticar: a linguagem era técnica e insuficiente para sanar suas dúvidas. Segundo eles, os médicos orientavam pouco sobre o tratamento medicamentoso, deixando-os com seus temores, como o de que o uso de múltiplos medicamentos pudesse matar ou causar coma permanente ${ }^{28}$.

Por fim, a experiência GAM também fez com que usuários investissem interesse no tema dos direitos, antes ausente do universo de suas preocupações. Eles passaram a reconhecer o direito de participar das decisões referentes ao seu próprio tratamento, ler seu prontuário e obter as informações que necessitassem. Passaram a participar mais frequentemente da gestão dos serviços em que eram atendidos. Outrossim, puderam ampliar a discussão sobre direitos, não ficando restritos à saúde, mas incluindo também condições de vida e acesso à moradia. Contudo, os Caps, de maneira geral, estabeleciam uma demarcação estrita dos espaços de possibilidade de exercício de direito por parte dos usuários em regra, as 'assembleias' e as associações de usuários. Segundo os usuários, nesses espaços, a participação era acolhida e respeitada, mas, quando o assunto dizia respeito à gestão de seu próprio tratamento, não se sentiam escutados. Particularmente, o direito de recusar o tratamento não era respeitado, sendo mencionadas atitudes como medicação forçada, via oral ou injetável, ou, na internação, a contenção física, além de ameaças de transferência para "um lugar pior"10,27,28(2896),29 ou de desencadeamento de uma crise, caso rejeitassem o tratamento prescrito.

\section{Considerações finais}

Apontamos o elo indissociável entre GAM e exercício de direitos e cidadania, que, na experiência nos serviços públicos de saúde no Brasil, possibilitou colocar em evidência sua potencialidade, mas também seus limites. Vimos que a GAM significou, para os usuários, 
um espaço de exercício de direitos, mas esse exercício não reverberou da forma esperada entre os profissionais nem nos processos de tomada de decisão instituídos pelos serviços. O caráter profundamente participativo da estratégia GAM, em total afinidade com princípios do SUS, vai de encontro a uma cultura há muito arraigada, de centralização do poder e hierarquização dos saberes, na qual o saber que advém da experiência dos usuários é pouco valorizado. A menos-valia desse saber encontra suas razões também na extrema desigualdade social, que impõe distância entre parte dos trabalhadores de saúde e os usuários no que se refere às condições de acesso a bens culturais, mesmo diante da crescente precarização desses trabalhadores.

Desse modo, embora a política de saúde brasileira professasse, aos seus usuários, direito à palavra, a ser respeitado como pessoa, a recusar ou questionar o tratamento proposto, e possibilidade de uma relação mais igualitária entre usuários e trabalhadores; embora esses preceitos pudessem ser aplicados, de fato, em muitos dos serviços substitutivos à lógica manicomial que a política de saúde mental brasileira propôs; não sem frequência, nós nos encontramos com trabalhadores e serviços apegados a antigos modelos, a repetir velhas formas não democráticas e hierarquizadas de relação com os usuários - formas que se repetem em diferentes esferas da vida societária dos brasileiros.

Por meio da GAM, esses usuários conquistavam uma experiência inédita de cidadania, que ganhava um sentido de dignificação da vida, como uma mudança de estatuto: do inumano ao humano, de objeto a sujeito. Isso não tem paralelo com a experiência GAM do Quebec, cuja democracia adquiriu suficiente alcance e estabilidade, garantindo direitos básicos a todos. Certamente, o adoecimento psíquico e a medicamentalização da vida geram estigma e perda de direitos, mas cidadania e respeito à pessoa são experiências acessadas anteriormente a adoecimento e tratamento, as quais se trata de resgatar. No Brasil, de democracia desigual e interrompida, cidadania é uma experiência a ser inventada. Para usuários da saúde mental, a participação em um grupo GAM pode ser um lampejo dessa invenção, que ganha força de transformação - sendo o grupo, nesse caso, por seu manejo cogestivo, lateralização das relações e compartilhamento de experiências, um componente da estratégia brasileira, catalisador de sua força transformadora ${ }^{15}$.

Contudo, se o gradiente de democracia e cidadania é um marcador importante da diferença entre o Quebec e o Brasil, deparamo-nos com o fato de que, no Quebec ou no Brasil, a trajetória GAM - tanto institucional quanto pessoal - enfrenta os mesmos desafios, ao buscar aumentar o poder dos usuários nas decisões que dizem respeito ao seu tratamento medicamentoso. É o mesmo muro contra o qual se bate a GAM: o dos diagnósticos estigmatizantes, do reducionismo biomédico, da medicamentalização da vida. Não importa o país, arriscamos dizer que os movimentos reformistas não alcançaram reformar o tratamento medicamentoso. $\mathrm{O}$ discurso biomédico se impõe como ente transnacional a serviço do controle dos corpos e da indústria farmacêutica. Pelo direito à vida, por mais democracia e por alternativas não medicalizantes de cuidado em saúde mental, a parceria entre Quebec e Brasil em torno à GAM encontra razões para seguir.

\section{Colaboradoras}

Palombini A (0000-0002-8332-8292)* contribuiu para concepção, planejamento, análise e interpretação dos dados; elaboração do rascunho e da versão final do manuscrito. Del Barrio LR (0000-0002-4451-8237)* contribuiu para concepção, planejamento, análise e interpretação dos dados; revisão crítica do conteúdo e elaboração da versão final do manuscrito.
*Orcid (Open Researcher and Contributor ID). 


\section{Referências}

1. Instituto Brasileiro de Geografia e Estatística. Pesquisa nacional por amostra de domicílios contínua. Rendimentos de todas as fontes 2017 [internet]. 2018. [acesso em 2019 jan 15]. Disponível em: https://agenciadenoticias.ibge.gov.br/agencia-sala-de-imprensa/2013-agencia-de-noticias/ releases/20843-pnad-continua-10-da-populacao-concentravam-quase-metade-da-massa-de-rendimentos-do-pais-em-2017.

2. Piketty T. Rapport sur les inégalités mondiales 2018 - synthèse. Version française. Laboratoire sur les inégalités mondiales [internet]. 2017. [acesso em 2019 jan 15]. Disponível em: https://wir2018.wid.world/files/ download/wir2018-summary-french.pdf.

3. Souza J. A ralé brasileira: quem é e como vive. Belo Horizonte: UFMG; 2009.

4. Fernandes F. Existe uma crise da democracia no Brasil? In: Fernandes F. Mudanças sociais no Brasil. São Paulo: Global; 2008, p. 93-113.

5. Holanda SB. Raízes do Brasil. São Paulo: Companhia das Letras; 1996.

6. Kilomba G. Memórias da plantação. Episódios de racismo cotidiano. Rio de Janeiro: Cobogó; 2019.

7. Amarante P, Nunes MO. A reforma psiquiátrica no SUS e a luta por uma sociedade sem manicômios. Ciênc. Saúde Colet. 2018; 23(6):2067-2074.

8. Correia LC, Almeida OM. A luta Antimanicomial continua! Problematizações sobre o manicômio judiciário na perspectiva da reforma psiquiátrica brasileira. Rev. De Direit. Mov. Soc. [internet]. 2018 [acesso em 2019 jan 15]; 3(2):319-347. Disponível em: https:// periodicos.unb.br/index.php/insurgencia/article/ view/19727/18192.

9. Stotz EN. Trajetórias, limites e desafios do controle social do SUS. Saúde debate [internet]. 2006 [acesso em 2019 jan 15]; 30(73-74):149-160. Disponível em: https:// www.redalyc.org/pdf/4063/406345309003.pdf.
10. Onocko-Campos R, Palombini AL, Silva AE, et al. Adaptação multicêntrica de um Guia para a Gestão Autônoma da Medicação. Interface [internet]. 2012 [acesso em 2019 jan 15]; (16):967-980. Disponível em: http://www.scielo.br/pdf/icse/2012nahead/aop4412. pdf.

11. Rodriguez del Barrio L, Cyr C, Benisty L, et al. Gaining Autonomy \& Medication Management (GAM): new perspectives on well-being, quality of life and psychiatric medication. Ciênc. Saúde Colet. 2013; 18(10):2879-2887.

12. Rodriguez del Barrio L, Poirel M. Émergence d'espaces de parole et d'action autour de l'utilisation de psychotropes: La Gestion autonome des médicaments de l'âme. Nouvelles pratiques sociales 2007; 19(2):111127.

13. Guerini LR. Da prescrição à tradução. Apoio institucional e matricial a partir da Gestão Autônoma da Medicação [dissertação]. Niterói: Universidade Federal Fluminense; 2015.

14. Onocko-Campos RT, Passos E, Leal E, et al. Guia da Gestão Autônoma da Medicação - GAM [internet]. 2018. [acesso em 2019 jan 15]. Disponível em: https:// www.fcm.unicamp.br/fcm/sites/default/files/paganex/guia_gam_para_dowload_com_correcoes.pdf.

15. Onocko-Campos RT, Palombini AL, Passos E, et al. Gestão Autônoma da Medicação: Guia de apoio a moderadores [internet]. 2014 [acesso em 2019 jan 15]. Disponível em: https://www.fcm.unicamp.br/ $\mathrm{fcm} /$ sites/default/files/paganex/guia_gam_moderador_-_versao_para_download_julho_2014.pdf.

16. Regroupement des Ressource Alternative en Santé Mentale du Québec, Association des Groupes d'Intervention en Défense des Droits en Santé Mentale du Québec, Équipe de Recherche et d'Action en Santé Mentale et Culture (Québec). Gestion autonome de la médication de l'âme. Mon guide personnel, Québec: RRASMQ ; AGIDD-SMQ; 2002. 
17. Regroupement des Ressource Alternative en Santé Mentale du Québec, Association des Groupes d’Intervention en Défense des Droits en Santé Mentale du Québec, Équipe de Recherche et d'Action en Santé Mentale et Culture (Québec). Mon guide personnel. Gestion autonome de la médication en santé mentale. Montreal: RRASMQ; AGIDD-SMQ; ÉRASME; 2017. Edição atualizada.

18. Bakhtin M. Estética da criação verbal. 5. ed. São Paulo: Martins Fontes; 2010.

19. Bakhtin M. Problemas da poética de Dostoievski. 3. ed. Rio de Janeiro: Forense-Universitária; 2005.

20. Gonçalves RW, Vieira FS, Delgado PGG. Política de Saúde Mental no Brasil: evolução do gasto federal entre 2001 e 2009. Rev. Saúde Púb. 2011; 46(1):51-58.

21. Passos E, Palombini AL, Onocko-Campos RT, et al. Autonomia e cogestão na prática em saúde mental: o dispositivo da gestão autônoma da medicação (GAM). Aletheia. 2013; (41):8-23.

22. Mol A. The logic of care. London and New York: Routledge; 2008.

23. Brasil. Ministério da Saúde. Carta dos direitos dos usuários da saúde. 3. ed. Brasília, DF: Ministério da Saúde; 2011.

24. Melo JJM. A política de narratividade entre a pesquisa e a clínica: relato de uma experiência com a Gestão Autônoma da Medicação [tese]. Niterói: Universidade Federal Fluminense; 2015.
25. Ferrer A, Palombini A, Azambuja M. Gestão Autônoma da Medicação: um olhar sobre dez anos de produção participativa em saúde mental a partir do Brasil. Rev Polis Psique. 2020; 10(2):1-8.

26. Marques CC, Palombini AL, Passos E, et al. Sobre mudar de lugar e produzir diferenças - A voz dos usuários de serviços públicos de saúde mental. Mnemosine [internet]. 2013; 9(1):106-126. Disponível em: http://www.fcm.unicamp.br/fcm/sites/default/files/ paganex/artigo_mnemosine.pdf.

27. Sade C, Barros LMR, Melo JJM, et al. O uso da entrevista na pesquisa-intervenção participativa em saúde mental: o dispositivo GAM como entrevista coletiva. Ciênc. Saúde Colet. 2013; 18(10):2813-2824.

28. Onocko-Campos RT, Passos E, Palombini AL, et al. A Gestão Autônoma da Medicação: uma intervenção analisadora de serviços em saúde mental. Ciênc. Saúde Colet. 2013; 18(10):2889-2898.

29. Palombini AL, Onocko-Campos RT, Silveira M, et al. Relações entre pesquisa e clínica em estudos em cogestão com usuários de saúde mental. Ciênc. Saúde Colet. 2013; 18(10):2899-2908.

\footnotetext{
Recebido em 03/01/2020

Aprovado em 11/05/2020

Conflito de interesses: inexistente

Suporte financeiro: não houve
} 